\title{
LOS FUNDAMENTOS CURRICULARES EN LA ENSEÑANZA DEL INGLÉS A DISTANCIA: UN ACERCAMIENTO A PARTIR DE LA TEORÍA Y DE LA REFLEXIÓN DE LA PRÁCTICA EDUCATIVA
}

\author{
Roxy Calderón Mora \\ Asesora nacional del Ministerio de Educación Pública \\ y Profesora de la Universidad Estatal a Distancia
}

Recibido 30-VIII-2004 • Aceptado 7-IX-2004

\begin{abstract}
Resumen: El presente artículo es un acercamiento a la sistematización de la experiencia de la Universidad Estatal a Distancia en el programa de Inglés para maestros; se pretende dar al lector una visión retrospectiva de los elementos curriculares de la carrera desde sus inicios en 1997. El artículo retoma los antecedentes de la enseñanza del inglés en I y II ciclo en la modalidad a distancia en Costa Rica. Además, a partir de la propia experiencia como tutora de la cátedra de inglés, se hace un recorrido teórico por los diferentes métodos de enseñanza en que se sustenta la metodología empleada; así mismo, se plantean los fundamentos curriculares que deben sustentar la enseñanza del inglés para maestros de primaria en una modalidad de educación a distancia. Finalmente, se ofrecen consideraciones finales que retoman la enseñanza del inglés como idioma extranjero y la modalidad de educación a distancia como elementos fundamentales que responden a los cambios económicos, políticos, culturales y sociales de la globalización.
\end{abstract}

Palabras clave: Inglés, Educación a distancia, Curriculum

\section{Introducción}

El papel de la educación en el desarrollo del capital humano es fundamental ya que las personas alrededor del mundo buscan alternativas para mejorar su calidad de vida. El conocimiento y el uso eficaz de una lengua extranjera constituye una herramienta esencial para enfrentar nuevos retos y adquirir múltiples oportunidades. En este sentido, la educación debe concebirse como "un proceso y no como un bien, como un proceso de cambio mediante el cual el hombre se desarrolla, informándose y transformándose él mismo e informando y transformando a los demás y al medio en que vive" (Pérez, 1971:22).

En el nivel de la educación superior, la formación del individuo y de la colectividad implica rasgos más complejos, dado que la formación en este nivel educativo está relacionada no solo con la adquisición de la cultura sino también, con el trabajo y el poder político. De tal manera que en el contexto de formación de maestros de inglés se deben incluir actividades que incorporen esquemas que provean estímulos académicos, lingüísticos, culturales y sociales; es decir, una formación integral 


\begin{abstract}
This article examines the curricular elements and the experience at the State Open University (UNED) in Costa Rica since 1997 in the program for I and II Cycle English teachers. Based on the author's experience as a tutor at UNED, the article provides a comprehensive review of the teaching of English as well as analysis of the teaching approaches that have been adapted and applied through time. Besides, the curricular foundations that a program designed for English school teachers should have is proposed. Finally, this study offers some general considerations regarding both the teaching of English as a foreign language and distance learning as tools to face the economic, political, cultural and social challenges of globalization.
\end{abstract}

Key words: English, distance learning, curriculum. le permitirá al futuro docente tener una visión amplia para enfrentar los procesos de enseñanza y aprendizaje de una forma apropiada que responde a la edad y el desarrollo físico y mental del niño.

El propósito de este artículo es contribuir en la elaboración de la fundamentación curricular de la carrera en la enseñanza del inglés en I y II ciclo que ofrece la Universidad Estatal a Distancia (UNED). Esto a partir de la reflexión de la propia experiencia como tutora de la carrera en mención, el recorrido histórico de sus orígenes en la Universidad, de la revisión teórica sobre los métodos que se han utilizado en la enseñanza del inglés como idioma extranjero y de los principios teórico-prácticos que han estado implícitos en la UNED.

El éxito de la educación a distancia está fundamentado en las estrategias metodológicas que sustentan la base filosófica y práctica de la carrera. La educación a distancia se ofrece para muchas disciplinas; no obstante, en este artículo solo se hace referencia a la enseñanza del inglés como lengua extranjera, tomando como base la experiencia de la UNED en este campo.

En el ámbito educativo, especialmente en la educación a distancia, se habla de mediación pedagógica; que se concibe como la función que el tutor realiza al adecuar los contenidos curriculares al nivel del estudiante y de satisfacer los requerimientos necesarios para que el estudiante los aprehenda, los haga suyos y los aplique en otros contextos.

Asimismo, el tutor juega un papel central en las relaciones sociales que se generan entre las personas que intervienen en los procesos educativos, sobre todo cuando estas relaciones tienen contacto con apoyos didácticos que emplean medios masivos de comunicación. Este papel consiste en mediar esas relaciones, facilitar la comunicación y contribuir a darle significatividad y sentido. En la Universidad Estatal a Distancia (UNED), el tutor realiza su función de mediador con el apoyo de los materiales impresos y los recursos audiovisuales elaborados con fines didácticos. 
Los profesores y estudiantes de la carrera de profesorado y bachillerato en Ciencias de la educación con concentración en la enseñanza del inglés de la UNED coinciden en que la mediación pedagógica del proceso educativo en esta modalidad presenta limitaciones, debido a la escasa accesibilidad que tienen los estudiantes al uso de tecnología avanzada. Como se puede observar, la mediación pedagógica es un concepto amplio que involucra diversos aspectos como la función del tutor y del estudiante, las relaciones sociales entre los participantes del proceso de enseñanza y aprendizaje, los métodos, las técnicas, los recursos, entre otros. En esta reflexión se aborda la mediación pedagógica desde los métodos utilizados en la enseñanza del inglés a distancia y desde los fundamentos curriculares.

El presente artículo se ha organizado en los siguientes apartados, con el fin de presentar al lector una estructura que permita visualizar el contexto educativo y la dinámica de la enseñanza del inglés como lengua extranjera en una modalidad poco tradicional.

- Antecedentes de la enseñanza del inglés a distancia. Se ofrecen nociones históricas de la enseñanza del inglés como lengua extranjera en Costa Rica a partir de 1997 con la creación de la carrera de profesorado y bachillerato en Ciencias de la educación con concentración en la enseñanza del inglés en I y II ciclo, de la UNED.

\section{- Metodología en la enseñanza} del inglés como lengua extranjera. Incluye una descripción de métodos considerados más significativos en la enseñanza del inglés.

- Fundamentos curriculares de la enseñanza del inglés a distancia. Este apartado se aborda desde la perspectiva epistemológica, psicológica y socio-política. Constituye un aporte para la carrera de la enseñanza del inglés de la UNED, dado que para su elaboración se ha tomado en cuenta no solo la opinión de tutores, estudiantes y la experiencia de la autora en el sistema a distancia sino también, se ha basado en principios teóricos que sustentan una posición teórico-práctica.

- Consideraciones finales. Se presenta una propuesta a la mediación pedagógica de la UNED en la carrera enseñanza del inglés en I y II ciclo a partir de la sistematización de la experiencia como tutora y los fundamentos y principios curriculares.

\section{Antecedentes de la enseñanza del inglés a distancia}

En Costa Rica, la educación a distancia se ofrece en el nivel de educación superior a partir de 1971, con la creación de la Universidad Estatal a Distancia, (UNED). Desde su creación, ofreció carreras en el campo de la educación, cubriendo todo el territorio nacional y llegando así a donde la educación presencial no podía hacerlo. La enseñanza a distancia es una oportunidad educativa no tradicional que permite enfrentar la crisis de la educación, por medio de una metodología novedosa apoyada en el uso de la tecnología moderna.

Los avances científico tecnológicos han traído cambios a nuestra población y mayores exigencias a los profesionales. Ante este proceso las universidades tienen que movilizarse y buscar medios para poder avanzar científica, tecnológica y académicamente; es por esto, que la incorporación del idioma inglés en la formación de profesionales se perfila como idóneo para cumplir con los objetivos de la oferta y la demanda del mercado mundial.

La iniciativa de la UNED, como entidad pública responsable de la educación superior, se fortalece durante el gobierno de José Figueres Olsen 1994-1998, quien propone la enseñanza de un segundo idioma en las escuelas públicas. Lo anterior se 
plasma en la Política Educativa Hacia el siglo XXI, aprobada en la sesión 82-94 del 8 de noviembre de 1994; al respecto establece que "se fomentará el aprendizaje de una lengua extranjera que permita aumentar el intercambio con otras culturas y, a partir de allí, entender mejor la propia" (Política Educativa, 1994:5). Ante la iniciativa se inició con un plan piloto, dado que el país no contaba con experiencia en este campo, ni había profesionales en la enseñanza del inglés para I y II ciclo.

El gobierno de Costa Rica se ve en la necesidad de contratar profesores de idioma de secundaria o personal no titulado con conocimiento intermedio del idioma inglés. La gran demanda de maestros, al firmarse el convenio, se debió a que la enseñanza del inglés en I y II ciclo no había sido considerada como un mercado laboral tanto por las universidades públicas como privadas de nuestro país. Para darle continuidad se crea en el Ministerio de Educación Pública, una oficina llamada PROLED (Programa de Lenguas Extranjeras), con el fin de ofrecer capacitación intensiva a los futuros maestros quienes debían ser sensibilizados con diferentes estrategias metodológicas reconocidas como eficaces para la enseñanza y aprendizaje de lenguas extrajeras en I y II ciclo.

Para responder al principio de calidad educativa y a los objetivos de la UNED, en el año 1995 el Ministerio de Educación Pública y la Universidad Estatal a Distancia firman un convenio para la enseñanza del inglés. En el convenio (acta 573), se señala que "la Universidad Estatal a Distancia se compromete a preparar profesionales serios en el área de las Ciencias de la educación con concentración en la enseñanza del inglés en I y II ciclo“ (UNED, 1995).

Durante los cinco años del convenio, la UNED graduó a 400 estudiantes con grado académico de Bachillerato en Ciencias de la educación con concentración en la enseñanza de inglés en I y II ciclo.

A finales del año 2000, el Ministerio de Educación decide no renovar el convenio con la UNED por razones presupuestarias. Por tal razón, la Universidad se hace responsable del desarrollo de la carrera que hasta la fecha cuenta con una demanda creciente en su matrícula.

De acuerdo con lo anterior, se observa la demanda en el aprendizaje del inglés y los esfuerzos de Costa Rica por satisfacer las necesidades educativas mediante la modalidad a distancia; no obstante, la universidad debe continuar realizando esfuerzos para dar respuesta a los retos del cambio y consolidar esta carrera mediante una educación de calidad amparada en una propuesta curricular sólida.

En la búsqueda de esta respuestas se han puesto en práctica diversos métodos de enseñanza, tomados de la modalidad presencial y adaptados para la modalidad a distancia. A partir de las diferentes técnicas y estrategias metodológicas utilizadas en la enseñanza de un segundo idioma se hace un recorrido por los métodos más utilizados en esta práctica educativa.

\section{Metodología en la enseñanza del inglés como lengua extranjera}

De acuerdo con el estudio diacrónico de la lingüística, la enseñanza de un lenguaje extranjero se remonta a los pueblos de la antigua Grecia, quienes desarrollaron una metodología práctica. Los Romanos fueron probablemente los primeros en estudiar un segundo idioma formalmente, ellos estudiaron griego con instrucción de tutores y esclavos. Europa en el siglo XVI contemplaba la enseñanza del latín como segundo idioma a los sacerdotes. En los siglos XVI y XVII el francés se convirtió en lengua franca, por lo que el estudio de un segundo idioma, como elemento comercial, se fue expandiendo.

En el siglo XIX y mediados del XX, el enfoque dominante en la enseñanza de un segundo idioma fue el enfoque de la traducción, el cual fue el más utilizado en todos 
los países interesados en la enseñanza de un idioma extranjero. Sin embargo, a mediados del siglo XIX, con el desarrollo de algunas disciplinas como la psicología, la sociología y la educación, se cuestionan los métodos aplicados y se considera tanto la naturaleza del lenguaje como la del aprendizaje.

En este sentido, la experiencia en la enseñanza y el aprendizaje del inglés ha dado origen a diferentes enfoques teóricometodológicos. Es difícil delimitar con precisión los momentos históricos en los cuales cada uno de los distintos enfoques ha sido utilizado, así como los aportes concretos que se han obtenido. El uso de los métodos está relacionado con los propósitos de los cursos; es por tanto que algunos docentes los continúan poniendo en práctica total o parcialmente.

A partir de lo anterior, se presenta una breve descripción de las principales características y el propósito de algunos de los métodos más utilizados en la enseñanza presencial de un idioma y que tienen influencia en la mediación pedagógica de la UNED. Se citan como relevantes el método clásico, el método directo, el método audio lingual, y los métodos humanistas.

\section{- El método clásico o gramatical}

El clásico o gramatical se enfoca en las reglas gramaticales, la traducción, memorización de vocabulario, conjugaciones y ejercicios escritos. Este método estuvo vigente por siglos, aún en tiempos recientes. (Brown, 2001). En la UNED, se ha utilizado para que el estudiante conozca y ponga en práctica las reglas gramaticales del inglés, pues se considera que un docente tiene la obligación de comprender las estructuras gramaticales del idioma que aprende con el propósito de utilizarlo en ambientes formales; por ejemplo, en la enseñanza del inglés como idioma extranjero a niños.

\section{- El método directo}

El método directo desarrollado por Berlitz en el siglo XX pero anteriormente usado por el francés Gouin, consiste en simular la realidad para aprender la lengua de la manera que lo hacen los niños al aprender su lengua materna. (Brown, 2001). Los estudiantes de la UNED, participan en cuatro talleres de asistencia obligatoria en cursos tales como conversación y fonética inglesa; mediante éste método se incrementa el uso del vocabulario, se introducen nuevas estructuras fonéticas y se corrigen errores de pronunciación. El estudiante habla libremente sin ser interrumpido; posteriormente, el profesor retoma los elementos lingüísticos que se deben mejorar.

\section{- El método audio lingual}

El método audio lingual está firmemente asentado en la lingüística estructural y la teoría psicológica conductista. Su énfasis está en las formas superficiales del lenguaje y en la cansina repetición de patrones gramaticales (Coleman, 1992). El método audiolingual es un método que se usó en el pasado; no obstante, a pesar de ser considerado por muchos lingüistas y psicólogos como superado, por ser un método estructurado, se considera, por la experiencia en esta modalidad, pertinente en la enseñanza del inglés para maestros. En la UNED, este método recobra importancia en la reproducción de sonidos ya que responde a lo planteado en el propósito general de los cursos de fonética; en éste se establece que el estudiante reproduzca de forma exacta el sonido que se estudia.

Los estudiantes de los cursos de fonética cuentan con una guía didáctica y el apoyo de casetes o disco compacto. Además, el estudiante debe asistir a cuatro talleres durante el cuatrimestre, tiempo que se dedica a cada curso de la carrera, durante el taller el tutor reproduce sonidos y se 
espera que el estudiante los repita, de la manera más apropiada, inglés "estándar", el cual responde a un inglés modelo ya establecido por entidades gubernamentales.

\section{- Los métodos humanistas}

A partir de la década de los setenta, la enseñanza de los idiomas dejó de ser una rama de la lingüística y se convirtió en una disciplina (Brown, 2001). Además, en esa década más que en cualquier otra, la investigación en el campo de la enseñanza y el aprendizaje de una segunda lengua tomó relevancia histórica. La revolución lingüística que creó Chomsky con el estructuralismo lingüístico, unida al reconocimiento de la psicología de la naturaleza afectiva e interpersonal en los aprendizajes, creó un clima propicio para la aparición de innovadores métodos basados en la naturaleza afectiva (Curran, 1972). Entre éstos podemos citar:

a) El aprendizaje comunitario de la lengua creado por Curran (1972), quien se inspiró en la visión de Carl Rogers sobre la educación, en la cual los miembros de un grupo en una sala de clase se consideran como un "grupo" más que como una "clase".

b) Sugestopedia es otro de los métodos de la década. Se basa en la ponencia del psicólogo búlgaro Lozanov (1979), quien afirma que el cerebro humano puede procesar gran cantidad de material si se le dan las condiciones para el aprendizaje, entre las que cita el relajamiento, dar el control de la mente al maestro, escuchar música suave, entre otras cosas.

c) The silent way, sus orígenes se remontan a los años setenta, el profesor guarda silencio cuando el estudiante habla con el apoyo de ayuda visual. Se caracteriza por la resolución de problemas anteponiendo el descubrimiento a la memorización. d) Respuesta física total, desarrollado por James Asher en 1977, el cual utiliza el principio de la actividad física asociada al lenguaje. Para Asher, la actividad motora es una función del hemisferio derecho cerebral, que debe preceder al procesamiento del lenguaje que se lleva a cabo en el hemisferio izquierdo. Según Asher, el papel del maestro consiste en ser director de escena de una obra, en la que los estudiantes son los actores (Larsen, 1989).

e) El método de aproximación natural, el rol del profesor es promover actividades que preparen al alumno a comunicarse en un nivel muy cercano al que ya posee. Krashen y Terrel (1983) definen tres momentos naturales por los cuales el aprendiz avanza: pre-producción, comprensión y producción.

Los métodos humanistas se desarrollaron en los setentas y aún constituyen criterios dignos de considerar y de poner en práctica dentro de un modelo que debe formar profesionales integrales; es decir, seres humanos competentes en el ámbito social, económico, político y cultural. Las dimensiones humanistas son un aporte significativo que permiten tanto a los docentes como a los alumnos sentir seguridad y motivación en una segunda lengua.

El compromiso humanista se expresa en el II Congreso Universitario de la UNED, mediante la misión de ofrecer a la sociedad costarricense una formación amplia, destinada a la comprensión y valoración del ser humano con formación holística e interdisciplinaria (UNED, 2000). La carrera de inglés está estructurada por niveles para desarrollar competencias cognitivas y comunicativas que permitan un aprendizaje significativo.

En este sentido, el método que utiliza el tutor de la UNED depende esencialmente del curso que imparte. El método y las técnicas, tal y como se expuso anteriormente, 
responden a las diferentes teorías; es decir, a partir de las nuevas tendencias de la lingüística, la psicología y la sociología se evidencia una evolución dinámica que busca responder de forma pertinente a las demandas sociales.

Consecuente con los diferentes métodos, en la actualidad, la enseñanza de la lengua hace énfasis en el uso de una metodología ecléctica, determinada por principios cognitivos, afectivos y lingüísticos que permiten percibir e interiorizar las conexiones necesarias entre la teoría y práctica en cada circunstancia en particular (Brown, 1996). La metodología ecléctica fundamentada a partir de principios pedagógicos apremia una educación holística donde se interpongan las necesidades e intereses de los estudiantes y se aprovechen todos los recursos disponibles para dicho fin.

A partir de la experiencia de la enseñanza del inglés en la modalidad a distancia y la metodología empleada en la adquisición de una lengua extranjera, se hace un planteamiento de los elementos epistemológicos, psicológicos y sociológicos que deben sustentar esta modalidad de enseñanza. A continuación se ofrece un acercamiento en la construcción de la fundamentación curricular de la carrera en la enseñanza del inglés a distancia.

\section{Fundamentos curriculares de la enseñanza del inglés a distancia}

A través de los fundamentos curriculares, se pretende contribuir en la propuesta curricular de la carrera de la enseñanza del inglés en la modalidad a distancia. A partir del contexto de enseñanza y aprendizaje del inglés como lengua extranjera en la UNED, se sustentan teóricamente los elementos epistemológicos, psicológicos y sociológicos del currículo. Para muchos especialistas de la lengua, los fundamentos en la enseñanza del inglés responden a los principios cognitivos, afectivos y lingüísticos, respectivamente. La clasificación por principios se fundamenta en la perspectiva hacia el uso de una metodología ecléctica.

\section{Fundamentación epistemológica en la enseñanza del inglés}

En esta sección se pretende aportar en relación con el referente epistemológico que fundamenta la enseñanza del inglés a distancia. De acuerdo con (Ferrater Mora, 1985:243), la epistemología puede ser definida como "una teoría del conocimiento científico para dilucidar problemas relativos al conocimiento cuyos principales aportes han sido extraídos de las ciencias. Generalmente, se le conocía como gnoseología”.

Lo epistemológico explica el proceso de construcción del conocimiento, esto es, cómo los seres humanos aprendemos y comprendemos la realidad y especialmente, cómo se relaciona con el entorno y consigo mismo. Este proceso no está exento de subjetividad, ya que esto se realiza mediante la percepción sensorial y la visión de mundo que se adopte, o bien desde la perspectiva de un modelo que permite tanto la comunicación con otros individuos, como la búsqueda de la explicación de esos fenómenos reales.

Si se asume la naturaleza social del conocimiento y del lenguaje, se podrían explicar los procesos de la adquisición de una segunda lengua como una actividad social. Sin embargo, los diferentes enfoques en la enseñanza y al aprendizaje se vierten en un torrente de controversias que generan incógnitas, tales cómo: ¿existe un periodo crítico para el aprendizaje de un segundo idioma? y ¿hay diferencias entre el aprendizaje de un primer y segundo idioma?

$\mathrm{Al}$ respecto Bley-Vroman (1988) establece que los adultos poseen habilidades generales para la adquisición de idiomas siempre y cuando exista un ambiente apropiado. Por su parte, White (1990) indica 
que cuando se aprende un segundo idioma el estudiante tiene que ajustar los parámetros establecidos por su primer idioma. Entre los principios cognoscitivos se citan los siguientes:

- Automaticidad: Mediante esta forma de aprendizaje, el individuo aprende subconscientemente la lengua, a través de un proceso inductivo, y sin pensar en ella. Es algo similar a lo que McLaughlin llamó "proceso automático con atención periférica de las formas de lenguaje" (McLaughlin: 1990).

- Aprendizaje significativo: este tipo de aprendizaje "sumerge" nueva información bajo estructuras existentes y sistemas de memoria, para crear eslabones de asociación para una mejor retención del aprendizaje. Esta forma de aprendizaje está fuertemente sustentada en las teorías cognitivas de Ausubel (1963). El aprendizaje significativo de los estudiantes depende en gran parte del conocimiento previo. El conocimiento previo representa las experiencias adquiridas a través de las actividades educativas que incluyen contenido, destrezas de las materias, de pensamiento y del idioma.

- La anticipación de recompensa: Skinner y otros conductistas, han demostrado claramente la fuerza que ejerce la recompensa, tanto en el comportamiento animal como en el de los seres humanos. El principio tras el cual el paradigma de los condicionantes operantes se puede resumir de la siguiente manera: "Universalmente, los seres humanos son llevados a actuar, o comportarse por la anticipación de algún tipo de recompensa, sea ésta tangible o intangible, a corto o a largo plazo, la cual se hará presente como respuesta a una conducta" (Kohn, citado por Brown, 2001:16).

En este sentido, la carrera en la enseñanza del inglés en I y II ciclo de la UNED privilegia el aprendizaje cognoscitivo. Lo anterior porque el estudiante que ingresa a carrera debe poseer como mínimo, un nivel intermedio en el dominio del inglés. A partir de este conocimiento, el tutor junto con el estudiante se centra en los procesos de desarrollo a partir de lo ya conocido. El rol del tutor es de instructor, el alumno es un ente social y protagonista de su propio conocimiento a partir de una motivación interna y externa.

Dentro de la concepción teórica de Delors, J. y otros (1996) se establecen los aprendizajes fundamentales para el desempeño profesional de un educador. Los aprendizajes fundamentales describen las competencias en relación con cuatro principios del aprendizaje: a) aprender a conocer, concebido como la competencia para aprender a aprender y la adquisición de conocimientos, b) aprender a hacer, concebido como la competencia que capacite al individuo para hacer frente a un gran número de situaciones profesionales y a trabajar en equipo c) aprender a vivir juntos, se concibe como la competencia para participar y cooperar con los demás en todas las actividades humanas en el desarrollo de proyectos comunes. Por último, d) aprender a ser, ofrece un proceso que incorpora elementos de mejoramiento de la propia personalidad con el propósito de aumentar su autonomía.

En este sentido, la fundamentación epistemológica en la formación de maestros en el área del inglés debe privilegiar estrategias metodológicas que respondan a los saberes con el propósito de que el estudiante en su desempeño profesional tenga la capacidad de poner en práctica sus conocimientos fomentando una actitud positiva.

El estudiante en la metodología a distancia debe ser una persona muy disciplinada ya que la distribución del tiempo de estudio es eminentemente fuera del aula; dado que en las sesiones presenciales, especialmente en los conocidos como talleres solamente se retoman ejercicios que por su importancia o nivel de dificultad requieren de mayor práctica. Por lo 
anterior, el saber "aprender a conocer" es un elemento implícito dentro de esta modalidad educativa. Los saberes "aprender a aprender", "aprender a hacer" y "aprender a vivir juntos" es parte de la convivencia y la realidad de cada curso de la carrera en mención. A partir de la experiencia de cada uno de los alumnos de esta carrera se espera que cuando éstos se integren en la labor docente de aula lo practiquen y lo vivan con sus estudiantes a partir de las estrategias de aprendizaje empleadas.

El aprendizaje de un segundo idioma por su naturaleza provoca gran inquietud en los estudiantes ya que el contexto diario en el cual se desenvuelven no permite una retroalimentación de su aprendizaje. Según la opinión de los estudiantes en la carrera de profesorado y bachillerato en Ciencias de la Educación con concentración en la enseñanza del inglés en I y II ciclo en la UNED, la necesidad de producción oral y escrita y de supervisión de un profesional en el campo, se convierte en una debilidad en los procesos de enseñanza y aprendizaje. Los mismos opinan que es necesario que se incorporen más talleres presenciales en cursos de conversación y composición inglesa. (Calderón, 2004).

La inquietud de los estudiantes por asistir a más talleres refleja incongruencia entre los principios de la UNED como única universidad en Costa Rica que ofrece la educación a distancia. Para solventar estas necesidades de los estudiantes de la enseñanza del inglés como idioma extranjero en la modalidad a distancia, se propone a partir de la experiencia la utilización de las herramientas tecnológicas. Entre los recursos tecnológicos que favorecen la educación a distancia y que deben ser elemento indispensable en la carrera de profesorado y bachillerato en Ciencias de la educación con concentración en la enseñanza del inglés en I y II ciclo de la UNED se mencionan las siguientes:

- Las herramientas instruccionales de sonido incluyen el teléfono, conferencias de audio, ondas de radio y casetes.
- Las herramientas instruccionales de vídeo incluyen imágenes tales como, filminas, imágenes prediseñadas, imágenes con movimiento y sonido.

- Las herramientas de tecnología moderna como la computadora con la que el estudiante tiene la posibilidad de enviar y recibir información electrónica. Las aplicaciones de la computadora en la educación a distancia son variadas para cursos tanto de expresión oral como escrita.

En este sentido, el uso de herramientas tecnológicas constituye un aporte medular. Así por ejemplo, un curso de composición donde el estudiante y el profesor tenga acceso a correo electrónico o a fax permite una retroalimentación individualizada. De esta manera, se puede solventar uno de los problemas más graves que manifiestan los estudiantes, en cuanto recibir retroalimentación y evaluación formativa en el proceso de aprendizaje.

Una efectiva educación a distancia debe responder a un planeamiento enfocado a la comprensión y a las necesidades de los estudiantes. La tecnología apropiada solo podrá ser seleccionada a partir del análisis de estos elementos. A partir de los principios en que se fundamentan los procesos de enseñanza y aprendizaje, se podría asumir que el estudiante en la modalidad a distancia es un ser activo capaz de aprender bajo ciertas circunstancias como la motivación, organización y análisis de los contenidos estudiados. Le corresponde al tutor, entre otras cosas:

- Desarrollar comprensión de las características y necesidades de los estudiantes a distancia.

- Adaptar la metodología a los diferentes estilos de aprendizaje considerando la diversidad de la audiencia.

- Desarrollar habilidades para el uso de recursos tecnológicos específicamente en su funcionamiento para el proceso de enseñanza y aprendizaje. 
- $\quad$ Conocer la temática y tener habilidad para transmitirla a través de recursos tecnológicos.

- Motivar a los estudiantes para que sientan confianza y motivación en el uso de recursos tecnológicos.

En la fundamentación curricular de la carrera de inglés a distancia, lo epistemológico es un tema apenas iniciado y éste no se desliga de lo cognitivo, lo afectivo y lo sociocultural. En consecuencia, es igualmente importante la fundamentación psicológica; considerada como el aporte al ser y a la autorrealización.

\section{Fundamentación psicológica en la enseñanza del inglés}

La fundamentación psicológica se centra en los procesos emocionales de las personas. Se tienen en cuenta los sentimientos de quienes aprenden la lengua en relación consigo mismos, en sus relaciones con los otros miembros de la comunidad de hablantes, y en relación con los lazos emocionales entre lengua y cultura (Brown, 2001). Entre los principios afectivos se pueden citar:

- El ego de la lengua: conforme la persona aprende a usar la segunda lengua, desarrolla una nueva forma de pensar, sentir y actuar, es decir, una nueva identidad. El nuevo "ego de la lengua", entretejido con el ego de su lengua materna, crea en quien aprende la segunda lengua un sentido de fragilidad e indefensión, así como el surgir de inhibiciones, debido a que sus carencias en la nueva lengua los hacen sentir incapaces. Es por eso que necesitan todo el apoyo afectivo del maestro (Brown, 1991).

- Autoconfianza: El eventual éxito que pueda alcanzar quien aprende una segunda lengua depende, en mucho, de la confianza en sí mismo y en sus habilidades para lograr su meta (Wright, 1990).

- Correr el riesgo: Un tercer principio afectivo, interrelacionado con los dos anteriores, consiste en hacer que quienes aprenden la lengua corran un riesgo calculado al intentar hacer uso de ella, tanto productiva como receptivamente. Si se tiene conciencia de las limitaciones del ego de la lengua y la determinación para aceptar el reto estarán listos para usar la nueva lengua con propósitos significativos. (Brown, 1996).

- La conexión lengua-cultura: Siempre que se enseña una lengua, también se enseña un sistema complejo de costumbres culturales, valores, formas de pensar, sentimientos y actitudes. Debido a la estrecha relación entre lengua y cultura, el aspecto principal de este principio se basa en esa compleja interconexión entre ambas (Brown, 1996).

El profesor de una lengua extranjera debe ser competente en las diferentes áreas de la disciplina; además, de poseer conocimiento de la cultura del idioma que se enseña. El estudio de una cultura es muy complejo y por lo tanto, no se aprende o enseña con un curso determinado, sino es mediante la experiencia que la persona logra comprender su cultura y la de los demás (Kohn, 1990).

Es indispensable que en el diseño de un plan de estudios en la enseñanza de un segundo idioma, tanto el elemento cultural como la comunicación deben considerarse como ejes curriculares en el plan de estudios. Puesto que el ser humano se apropia de su cultura por medio del lenguaje, la mediación pedagógica que fomenta el quehacer universitario debe tener una concepción que responda a los intereses de la sociedad y que sirva de línea de acción para la propuesta educativa.

Dentro de los principios afectivos, la motivación es un elemento indispensable 
que garantiza el éxito de una propuesta educativa. La motivación es en sí misma una actitud del estudiante y del profesor, determinada por factores internos y factores externos. La globalización del conocimiento ha permitido al estudiante de la carrera de profesorado y bachillerato en Ciencias de la Educación con concentración en la enseñanza del inglés en I y II ciclo en la UNED estar anuente a conocer otras culturas y por ende valorar el aprendizaje diario.

A partir de la reflexión de los elementos epistemológicos y psicológicos que influyen en la enseñanza del inglés como idioma extranjero en la modalidad a distancia, se hace referencia a la fundamentación sociológica esto debido a que el aprendizaje de una lengua es producto de un proceso socioeconómico y político.

\section{Fundamentación sociológica en la enseñanza del inglés}

Partiendo de la premisa que el lenguaje es comunicación, la comunicación es expresión oral y expresión escrita; ambas nos permiten el desarrollo humano como una unidad biopsicosocial; es decir, mediante el lenguaje el ser humano desarrolla la dimensión emocional, intelectual y la social.

El aprendizaje es una interacción que otorga importancia al entorno sociocultural y el lenguaje constituye la principal forma de medición, pues asegura la participación de los individuos en los procesos de la sociedad y de la historia. En este sentido, el enfoque comunicativo y funcional de la enseñanza del inglés demanda procesos educativos que permitan el uso del idioma tanto en forma oral como escrita.

El objetivo principal de la enseñanza del inglés como idioma extranjero debe ser el desarrollo de la competencia comunicativa del estudiante. Es decir, mediante cursos de expresión oral y escrita, el estudiante aprende a usar la lengua, en el sentido de producir y comprender textos orales y escritos atendiendo la correcta articulación de las palabras y su ordenamiento en las frases y oraciones.

Aprender el inglés como idioma extranjero significa eficacia en la actuación social como emisor, puesto que el hablante estará en condiciones de planificar su propio discurso, tanto oral como escrito, y como receptor, captará las características de la producciones lingüísticas de los otros hablantes.

Los fundamentos sociológicos son coherentes con los principios lingüísticos los cuales se centran en la forma en que la persona se enfrenta a los sistemas lingüísticos. Entre los principios lingüísticos más importantes a considerar están:

- El efecto de la lengua materna: la lengua materna es un factor determinante en el proceso de adquisición de la segunda lengua. Ese efecto actúa en dos sentidos: por una parte, interfiere en el proceso, ya que algunos de los errores que comete el nuevo hablante de la lengua se deben a que éste asume que la segunda lengua opera igual que su propia lengua. Por otra parte, actúa como un elemento facilitador ya que el aprendiz de la segunda lengua cuenta con un esquema que le permite desarrollar destrezas y habilidades a partir de los conocimientos previos en la comunicación oral y escrita. (Brown, 2001).

- La competencia comunicativa: Éste es quizá el principio lingüístico más importante en el proceso enseñanzaaprendizaje de una lengua, ya que la meta en la sala de clase debe ser dar al estudiante los elementos necesarios para que logre comunicarse apropiadamente en la nueva lengua. En este sentido:

"Para lograr la competencia efectiva, la instrucción debe apuntar hacia los componentes: organizacional, 
pragmático, estratégico y psicomotor. Se le debe prestar más atención al uso de la lengua que al tratamiento de la misma; a la fluidez, y no a la precisión; al lenguaje auténtico y los contextos, y a las necesidades eventuales del estudiante de aplicar lo aprendido en clase en el mundo real." (Savignon; 1991:275).

Este planteamiento resalta la variación lingüística originada por los factores sociales y culturales, ampliando la noción de competencia al proceso comunicativo. El marco de referencia de la actividad lingüística no es solo una lengua en particular sino una comunidad en contexto.

Desde esta perspectiva, el concepto de tarea comunicativa se sustenta en la idea de que una gramática no se internaliza sobre su estructura; sino, de manera inconsciente, como resultado de un proceso interior desencadenado al querer resolver una necesidad de comunicación. La necesidad de comunicación es creada por la propia estructura de la tarea que el alumno debe resolver.

El alumno se concentra en la solución de la tarea y "se olvida" que está en clase de lengua extranjera $y$, en consecuencia, aprende distraídamente, inconscientemente, jugando, pensando y/o creando. Así, el elemento fundamental de la tarea es la existencia de un proceso de raciocinio cuya base de aprendizaje es la experiencia laboral, la reflexión, la conceptualización abstracta y la acción. El alumno aprende a comunicarse mediante la interacción en la segunda lengua, sea con los compañeros, los profesores o los textos.

A partir del aporte social, el aprendizaje del inglés cumple, principalmente, una función comunicativa. En la educación de adultos estos aspectos son elementos esenciales que permiten formar a los profesionales desde una percepción real de lo que será el campo laboral. El estudiante de carrera en sus primeros niveles tiene cursos muy estructurados; por ejemplo, gramática I; no obstante posteriormente la gramática queda implícita en cursos como los de Literatura, en los cuales los estudiantes expresan sus ideas a través de ensayos académicos.

Otro elemento social que repercute en la enseñanza de un segundo idioma es el aspecto socioeconómico y sociopolítico. A partir de la dimensión social, el perfil del graduado en Costa Rica y específicamente en la UNED se orienta hacia las necesidades socio-económicas del país, pues se intenta vincular la carrera de la enseñanza del inglés con el logro de dos propósitos básicos: solventar la necesidad de profesionales en esta área del conocimiento y formar a las nuevas generaciones con conocimientos en la lengua que, comercialmente, ocupa el primer lugar en el mundo en materia de tratados y relaciones internacionales.

El componente socio-político en la enseñanza del inglés como lengua extranjera es una consecuencia del impacto cultural que la boga anglosajona ha penetrado en los países latinoamericanos. La formación de maestros de inglés en Costa Rica en el año de 1997 responde a un mandato gubernamental con carácter emergente. Se trata de brindar a los estudiantes un bagaje cultural y tecnocrático de la enseñanza del idioma inglés en términos de promover la inserción de los ciudadanos a un mercado de competencia laboral y profesional.

Como conclusión se ofrecen consideraciones finales en las cuales desde la perspectiva de la planificación curricular se enfatiza en la importancia de una visión integral del ser humano en la cual los elementos teóricos y prácticos de la carrera enseñanza del inglés para I y II ciclos en la modalidad de educación a distancia constituyen una respuesta a la demanda social, política y cultural de Costa Rica.

\section{Consideraciones finales}

El aporte principal de este artículo es contribuir en la elaboración de los fundamentos curriculares en la enseñanza del inglés a distancia. Esto constituye un 
acercamiento con la realidad educativa de la carrera enseñanza del inglés en I y II ciclo que imparte en la Universidad Estatal a Distancia. La misma es una oferta educativa reciente en nuestro país, ya que anterior a 1997 ninguna universidad pública o privada había considerado a las escuelas primarias de Costa Rica como campo laboral en la enseñanza del inglés.

Las consideraciones anteriores indican que la educación es un proceso dinámico que debe responder al cambio social, político, económico y cultural. En Costa Rica este proceso se evidencia en las tendencias globalizadoras a partir de la década de los noventa. Durante esta época, las necesidades y exigencias sociales promueven una visión de hombre con conocimientos sólidos en una lengua extranjera. Para los propósitos de esta época, es el idioma inglés el que se perfila como el idóneo para cumplir con los objetivos de la oferta y la demanda del mercado mundial.

El inglés es considerado como el segundo idioma más hablado mundialmente por el número de personas que lo usan como lengua materna, segunda lengua o lengua extranjera. El aprendizaje del inglés como idioma extranjero persigue la comunicación y permite al ser humano tener acceso a una amplia gama de información científica, tecnológica y humanista escrita en este idioma. Además, el uso de un segundo idioma desarrolla en el ser humano habilidades lingüísticas que favorecen las relaciones interculturales. Se considera que la experiencia de Costa Rica en la mediación pedagógica del inglés responde a la exigencia que tiene el país de competir en los mercados internacionales con las mejores condiciones individuales y sociales, y prevenir las necesidades para los años venideros.

La metodología en los procesos de enseñanza y aprendizaje es un elemento determinado por la práctica misma. Lo ideal es la utilización de recursos variados que permitan una mediación efectiva considerando las necesidades individuales y grupales. Una mediación apropiada solo podrá ser seleccionada a partir del análisis y comprensión de las necesidades de los estudiantes. La metodología empleada en la UNED para formar maestros de inglés es producto de una adaptación a los diferentes métodos que históricamente se han desarrollado.

Para que los propósitos en la enseñanza y aprendizaje del inglés como lengua extranjera se concreten, los recursos y estrategias de aprendizaje deben ser analizadas por el docente y la universidad. La educación a distancia tiene sus particularidades en cuanto a los intereses y necesidades de la población meta.

En este sentido, el uso de recursos tecnológicos por parte del tutor y el alumno es una prioridad en la modalidad. No hay que olvidar; sin embargo, que la tecnología no hace que los docentes dejen de ser indispensables, sino que modifica su función mediatizadora en relación con el proceso de enseñanza y aprendizaje.

La fundamentación de la carrera enseñanza del inglés en la modalidad a distancia debe tener como base los cuatro aprendizajes fundamentales el saber "aprender a conocer", "aprender a aprender", "aprender a hacer" y "aprender a vivir juntos". Además se debe sistematizar y fortalecer los elementos epistemológicos, psicológicos y sociales presentes en la misma. El perfil del futuro profesional debe responder a un individuo capaz de descubrir fortalezas y debilidades individuales y sociales a partir de una dimensión humanista que integre los elementos internos y externos del entorno que afectan directa e indirectamente el desenvolvimiento del ser humano.

La Universidad Estatal a Distancia debe dar respuesta, especialmente, a dos de los retos del presente siglo; por un lado, ofrecer la educación a distancia, modalidad que responde a la dinámica social, pues esta modalidad promueve la equidad entre estudiantes con experiencias variadas en cuanto estatus económico, social y cultural. Los estudiantes 
en la UNED cuentan con la posibilidad de estudiar ya sea por actualización o por la obtención de un grado universitario. Por otro lado, ofrecer la posibilidad de formar profesionales en la enseñanza del inglés en un campo nuevo y de gran demanda social, inglés para I y II Ciclos.

Mediante la fundamentación curricular y la sistematización de la experiencia en la UNED, en el campo del inglés como lengua extranjera para formar maestros en primaria, se pretende enriquecer la mediación pedagógica. La complejidad de los procesos de enseñanza y aprendizaje obliga al uso de estrategias de enseñanza que respondan al propósito de preparar a las nuevas generaciones para convivir, compartir y cooperar en el desarrollo del país a los principios cognitivos, afectivos y lingüísticos. La carrera debe promover una perspectiva integradora en la formación del futuro profesional que forme una visión prospectiva de formación de competencias profesionales con aprendizajes mayores o comprensivos.

\section{Referencias bibliográficas}

Anthony, E. Approach, method, technique. New York:Cambridge University Press. 1963.

Ausbel, D. Cognitive structure and the facilitation of meaningful verbal learning. Journal of Teacher Education. 1963.

Ausbel, D. Educational psychology: a cognitive view. New York: Holt, Rinehart and Winston. 1968.

Brown, H. D. Breaking the language barrier. New York: Intercultural Press. 1991.

Brown, H. D. Teaching by Principles. $2^{\text {nd }}$ edition. New Jersey: Prentice Hall Regents. 2001.
Calderón, R. [Entrevista con profesores y estudiantes de la carrera de inglés para I y II ciclo.] San José, Costa Rica Universidad Estatal a Distancia. 2004, abril.

Calderón, R. [Entrevista con Yinnia Mora Ordóñez, Encargada de Programa Universidad Estatal a Distancia]. San José, Costa Rica. 2004, marzo.

Coleman, A. The teaching of modern languages in the United States. Macmillan Company. 1992.

Delors, J. La educación encierra un tesoro. Madrid, España: Ediciones UNESCO. 1996.

Escotet, M. Tendencias de la educación a distancia. 2 da edición. San José, Costa Rica: EUNED. 1980.

Escuela Ciencias de La Educación y Humanidades. Macro-programación de la carrera de inglés. San José: Costa Rica; UNED. 1995.

Ferrater, J. Diccionario de filosofía. Madrid, España: Alianza Editorial, S.A. 1985.

Francisco, G, Daniel y otros. La mediación pedagógica: apuntes para la educación a distancia alternativa. Sexta edición. Ediciones Circus, La Crujía. 1999.

Kitao, Kn . History of English teaching methodology. Recuperado el 21 de marzo de 2004, de http://www.ling. lancs.ac.uk/staff/visitors/kenji/kitao/ tesl-his.htm

Krashen, S, and Terrel, T. The natural approach: language acquisition in the classroom. Pergamon Press. 1983. 
Larsen, D. Techniques and principles in language teaching. Oxford University Press. 1989.

Malave, L. Fundamentos cognitivos: la enseñanza del inglés como segundo idioma mediante un enfoque multidisciplinario. Recuperado el 31 de marzo de 2003, de http:// www.ncela. gwu.edu/miscpubs/ nysabe/vil11/nysabe111.pdf.

McLaughlin, B: Theories of second language learning. Pérgamo Seabury Press. 1987.

Ministerio de Educación Pública. Despacho del Ministro. Política educativa hacia el siglo XXI. San José, Costa Rica. 1994.

Nunam, D. The learners center curriculum. U.S.A. Cambridge. 1998.
Sarramona, J. Conceptualiza-ciones pedagógicas. España: Ediciones Morata. 1998.

Universidad Estatal a Distancia. Estatuto orgánico. San José, Costa Rica. 1983.

Universidad Estatal a Distancia. Instructivo de matrícula. San José, Costa Rica: EUNED. 2003.

Universidad Estatal a Distancia. II Congreso Universitario. San José, Costa Rica. 2000.

Villarini, A. El currículum orientado hacia el desarrollo humano integral. Río Piedras, Puerto Rico: Biblioteca del Pensamiento Crítico. 1996.

Wright, T. Understanding classroom relationships. Cambridge University Press. 1990. 
